\title{
Agrobacterium tumefaciens-mediated transformation of Lasiodiplodia theobromae, the causal agent of gummosis in cashew nut plants
}

C.R. Muniz ${ }^{1}$, G.F. da Silva ${ }^{2}$, M.T. Souza Jr. ${ }^{3}$, F.C.O. Freire ${ }^{1}$, G.H.J. Kema ${ }^{4}$ and M.I.F. Guedes ${ }^{5}$

\author{
${ }^{1}$ Embrapa Agroindústria Tropical, Fortaleza, CE, Brasil \\ ${ }^{2}$ Laboratório de Biologia Molecular, Embrapa Amazônia Ocidental, \\ Manaus, AM, Brasil \\ ${ }^{3}$ Embrapa Agroenergia, Parque Estação Biológica, Brasília, DF, Brasil \\ ${ }^{4}$ Biointeractions and Plant Health, \\ Plant Research International B.V., Wageningen, The Netherlands \\ ${ }^{5}$ Universidade Estadual do Ceará, Centro de Ciência da Saúde, \\ Fortaleza, CE, Brasil \\ Corresponding author: C.R. Muniz \\ E-mail: celli.muniz@embrapa.br / cellimuniz@gmail.com
}

Genet. Mol. Res. 13 (2): 2906-2913 (2014)

Received May 8, 2013

Accepted September 20, 2013

Published February 21, 2014

DOI http://dx.doi.org/10.4238/2014.February.21.8

\begin{abstract}
Lasiodiplodia theobromae is a major pathogen of many different crop cultures, including cashew nut plants. This paper describes an efficient Agrobacterium tumefaciens-mediated transformation (ATMT) system for the successful delivery of T-DNA, transferring the genes of green fluorescent protein $(g f p)$ and hygromycin B phosphotransferase ( $h p h)$ to $L$. theobromae. When the fungal pycnidiospores were co-cultured with $A$. tumefaciens harboring the binary vector with $h p h-g f p$ gene, hygromycin-resistant fungus only developed with acetosyringone supplementation. The cashew plants inoculated with the fungus expressing GFP revealed characteristic pathogen colonization by epifluorescence microscopy. Intense and
\end{abstract}


bright green hyphae were observed for transformants in all extensions of mycelium cultures. The penetration of parenchyma cells near to the inoculation site, beneath the epicuticle surface, was observed prior to 25 dpi. Penetration was followed by the development of hyphae within invaded host cells. These findings provide a rapid and reproducible ATMT method for L. theobromae transformation.

Key words: Lasiodiplodia theobromae; Cashew plants; Gummosis; Agrobacterium tumefaciens-mediated transformation

\section{INTRODUCTION}

Lasiodiplodia sp causes gummosis on cashew nut plants. This exudative disease was initially described by Freire (1991) in the cashew plantations of Ceará State (Brazil). Lasiodiplodia theobromae (Pat.) Griff. \& Maubl. (syn. Botryodiplodia theobromae) is now recognized as a major pathogen of cashew nut plants in northeast Brazil. Initial symptoms appear as a wound in the trunk that evolves into a gum exudative canker and, soon after, the yellowing of the leaves and plant decay. Protective measures are not available, with treatments remaining inefficient (Cardoso et al., 2010). In addition to cashew plants, L. theobromae negatively impacts several different crop cultures, including avocado (Persea americana Mill.), (Citrus spp), coconut (Cocus nucifera L.), (Eucalyptus sp), cassava (Manihot esculenta Crantz), melon (Cucumis melo L.), guava (Psidium guajava L.), mango (Mangifera indica L.), and papaya (Carica papaya L.), among others (Freire et al., 2004).

Previous microscopy studies of this pathosystem have revealed the extensive distribution of the fungus within the vessels of the secondary xylem, resulting in the infection of the xylem parenchyma. Infection causes clear cell wall disintegration, with the hyphae dispersing throughout the vascular cylinder, which is undoubtedly used by the fungus for enhancing hyphal distribution (Muniz et al., 2011). Specific genes might be involved during this severe pathogenicity process; hence, transformation protocols could be used to advance studies on plant-pathogen interactions.

Fluorescent reporter proteins are important tools that are used in a variety of techniques to understand plant-pathogen interactions. The $g f p$ gene encoding the green fluorescent protein (GFP) is widely employed as a fluorescence marker in many different filamentous fungus transformation protocols. Such protocols aim to image live-cell components during colonization or infecting processes (Nizam et al., 2010), to observe the dynamics of protein secretion in vivo (Ward, 2012), to test the function of cloned genes, to tag and clone pathogenicity genes, and to disrupt undesirable genes through insertional mutagenesis (Casas-Flores et al., 2004).

Agrobacterium tumefaciens-mediated transformation (ATMT) offers superior advantages for many different transformation methods for filamentous fungi. Such advantages include a high efficiency in transformation, a high percentage of single T-DNA insertion (Blaise et al., 2007), and the possibility to operate on distinct types of cells, spores, hyphae, or fructifications (Michielse et al., 2005). ATMT has been long used to transfer genes to a wide variety of fungi, including plant pathogenic or symbiotic fungi, mushrooms, industrial fungi, and biological control fungi (Ando et al., 2009; Sharma and 
Kuhad, 2010; Vieira and Camilo, 2011). A. tumefaciens has the natural ability to transfer a segment of its Ti plasmid, known as 'T-DNA' to plant or fungal cells, becoming randomly integrated into nuclear chromosomes. The binary vector system may be used by ATMT. In this system, T-DNA and the virulence region are separated in 2 distinct plasmids, allowing easier genetic manipulation of the smaller binary vector containing the T-DNA (Hoekema et al., 1983).

To date, transformation protocols for Lasiodiplodia species have not been described; yet, the members of this genus are largely implicated in several pre- and post-harvest problems for many tropical and sub-tropical plants. In the present study, we report the first ATMT of Lasiodiplodia. The development of a reliable and efficient transformation system for $L$. theobromae is important for the further elucidation of gene function related to pathogenicity and virulence, which are also facilitated by epifluorescence microscopy. This information is anticipated to open up the possibility of targeted molecular improvements for the purpose of biological control.

\section{MATERIAL AND METHODS}

\section{Source and growth conditions of microorganisms}

The wild-type strain L. theobromae Lt19 was previously isolated from diseased cashew plants, located in Brazilian Northeastern region. The strain was stored at $5^{\circ} \mathrm{C}$ on potato dextrose agar (PDA) (Muniz et al., 2012). Escherichia coli strain DH5 $\alpha$ was used as a host for the propagation of plasmid DNA. A. tumefaciens strain AGL1, which houses the binary vector, was maintained on Luria-Bertani (LB) medium supplemented with $250 \mu \mathrm{g} / \mathrm{mL}$ spectinomycin.

\section{Plasmid}

The backbone of pPm43GW (VIB, Gent, Belgium) was used to construct the binary vector to transform $L$. theobromae strain Lt19. It contains the cassette in which the $E$. coli hygromycin B (Hyg B) phosphotransferase ( $h p h)$ resistance gene is under the regulation of the Aspergillus nidulans trpC promoter and the PtGFP cassette, which contains the promoter toxA-5'-UTR from Pyrenophora tritici-repentis, the marker gene sGFP, and the nos terminator (Tnos). The resulting plasmid was named as pPm43GW-GFP-HPH (Figure 1). This vector was transformed into A. tumefaciens strain AGL1 using the electroporation method. The vector was spread onto an LB plate supplemented with $250 \mu \mathrm{g} / \mathrm{mL}$ spectinomycin, and incubated at room temperature for 2 days.

\section{Sensitivity to hygromycin B test}

Before transformation, cultures obtained from germinated pycnidiospores (Muniz et al., 2012) were submitted to the minimum inhibitory concentration of hygromycin B. Cultures were inoculated on PDA, containing different concentrations of hygromycin B $(0,50,100$, $150,200,250$, and $300 \mu \mathrm{g} / \mathrm{mL}$ ) and, then, incubated at $28^{\circ} \mathrm{C}$ for 14 days. For each treatment, 5 Petri dishes were used. Hygromycin B concentration that fully inhibited the mycelial growth of all 5 plates was used in the transformation experiment. This test was repeated twice. 


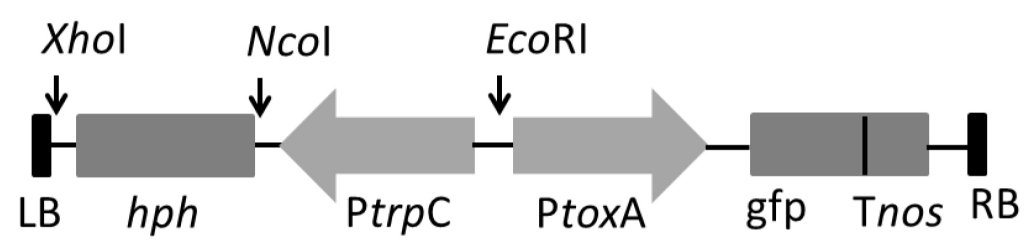

Figure 1. Schematic representation of cassette $h p h$-gfp cloning in the gateway destination binary vector pPm43GW (VIB, Gent, Belgium). The plasmid was constructed for the Agrobacterium-mediated transformation of Lasiodiplodia with the $g f p$ gene placed under the promoter PtoxA-5'-UTR from Pyrenophora tritici-repentis (right arrow) and the Tnos terminator. The selection marker is the Escherichia coli hygromycin B phosphotransferase $(h p h)$ resistance gene under the regulation of the Aspergillus nidulans trpC promoter (left arrow). LB and RB represent left and right borders.

\section{Fungal transformation}

Transformation was performed as previously described (de Groot et al., 1998; dos Reis et al., 2004; Staats et al., 2007), with minor modifications. Isolated colonies of $A$. tumefaciens, strain AGL1, were grown in $20 \mathrm{~mL} \mathrm{LB}$ mannitol (10 g bacto-peptone, $5 \mathrm{~g}$ yeast extract, $2.5 \mathrm{~g} \mathrm{NaCl}, 10 \mathrm{~g}$ mannitol) that was supplemented with $250 \mu \mathrm{g} / \mathrm{mL}$ spectinomycin and $75 \mu \mathrm{g} / \mathrm{mL}$ carbenicilline overnight at $27^{\circ} \mathrm{C}, 150 \mathrm{rpm}$. Subsequently, A. tumefaciens cells were centrifuged and resuspend in $20 \mathrm{~mL}$ minimal medium (MM) $\left(11.4 \mathrm{mM} \mathrm{K}_{2} \mathrm{HPO}_{4}, 10.6\right.$ $\mathrm{mM} \mathrm{KH} \mathrm{PO}_{4}, 2.4 \mathrm{mM} \mathrm{MgSO} \cdot \cdot 7 \mathrm{H}_{2} \mathrm{O}, 5.4 \mathrm{mM} \mathrm{NaCl}, 68 \mu \mathrm{M} \mathrm{CaCl}_{2} \cdot 2 \mathrm{H}_{2} \mathrm{O}, 6.6 \mu \mathrm{M} \mathrm{FeSO}_{4}$, $1.74 \mathrm{mM} \mathrm{ZnSO}_{4} \cdot 7 \mathrm{H}_{2} \mathrm{O}, 2 \mathrm{mM} \mathrm{CuSO}_{4} \cdot 5 \mathrm{H}_{2} \mathrm{O}, 8 \mathrm{mM} \mathrm{H}_{3} \mathrm{BO}_{3}, 2.96 \mathrm{mM} \mathrm{MnSO} \cdot \cdot \mathrm{H}_{2} \mathrm{O}, 2 \mathrm{mM}$ $\mathrm{Na}_{2} \mathrm{MoO}_{4} \cdot 2 \mathrm{H}_{2} \mathrm{O}, 6.3 \mathrm{mM} \mathrm{NH} \mathrm{NO}_{3}, 11 \mathrm{mM}$ glucose) containing $75 \mu \mathrm{g} / \mathrm{mL}$ carbenicilline and $250 \mu \mathrm{g} / \mathrm{mL}$ spectinomycin. After incubation overnight at $27^{\circ} \mathrm{C}, 150 \mathrm{rpm}$, the culture was diluted to $\mathrm{OD}_{660}$ of 0.15 in $20 \mathrm{~mL}$ induction medium (IM) (same as MM, but amended with $40 \mathrm{mM}$ (2-[N-morpholino]ethanesulfonic acid), $54 \mathrm{mM}$ glycerol, and $200 \mu \mathrm{L}$ acetosyringone (AS), containing $75 \mu \mathrm{g} / \mathrm{mL}$ carbenicilline and $250 \mu \mathrm{g} / \mathrm{mL}$ spectinomycin. The culture was returned to the same growth conditions until $\mathrm{OD}_{660}$ reached 0.25. L. theobromae monosporic strain Lt 19 was grown on PDA at $28^{\circ} \mathrm{C}$ for 14 days. Pycnidiospores were obtained according to the method of Muniz et al. (2012), were collected by flooding the Petri dish with sterile water, and counted under a Zeiss microscope with a Neubauer chamber. The final pycnidiospore concentration was adjusted to $10^{7}$ spores $/ \mathrm{mL}$ in saline solution. Co-cultivation between $A$. tumefaciens and pycnidiospores solution was performed by adding $100 \mu \mathrm{L}$ bacterial culture to $100 \mu \mathrm{L}$ fungal suspension. This mixture was placed onto squared membranes of cellulose $(120 \times 120 \times 17 \mathrm{~mm})$ on a co-cultivation medium (IM $+1.5 \%$ agar $)$, in the presence and absence of $200 \mu \mathrm{L} \mathrm{AS}$, and incubated for 2 days at $22^{\circ} \mathrm{C}$. After 2 days, the samples were transferred to selection medium (SM) amended with $150 \mu \mathrm{g} / \mathrm{mL}$ hygromycin and $200 \mu \mathrm{M} /$ $\mathrm{mL}$ cefotaxime, to inhibit $A$. tumefaciens growth. The colonies that appeared after incubation at $28^{\circ} \mathrm{C}$ (putative transformants) were transferred to PDA with $150 \mu \mathrm{g} / \mathrm{mL}$ hygromycin and incubated at $28^{\circ} \mathrm{C}$.

\section{Transgene stability and viability of Lasiodiplodia transformants}

All transgenic isolates from ATMT of Lasiodiplodia were subcultured on PDA 
amended with $150 \mu \mathrm{g}$ hygromycin. The plates were incubated at $28^{\circ} \mathrm{C}$ for 8 days. Every 2 days, the colony growth rate was checked. After 8 days, pycnidiospores production was tested. This procedure was successively repeated 3 times. Fungal colonies were then analyzed for GFP expression.

\section{Plant inoculation}

Cashew plants originated from the seeds of open-pollinated dwarf cashew clone CCP 76 trees, developed by the Brazilian Agricultural Corporation (EMBRAPA). The stems of ten 2-month-old plants were inoculated with the mycelium of transformants by using a small electrical drill to make the hole in which the mycelium was placed, and then the hole was covered with tape. The infected plants were incubated in a growth chamber at $25^{\circ} \mathrm{C}$, with $60-70 \%$ relative humidity, a photoperiod of 12 -h light/12-h dark, and approximately $180 \mu \mathrm{mol} \cdot \mathrm{m}^{-2} \cdot \mathrm{s}^{-1}$ photosynthetically active radiation, using Lentse potgrond (Hortimea, Elst, The Netherlands) potground as the substrate. The progress of the disease was monitored weekly for 4 weeks. Specifically, 2 x $2-\mathrm{cm}$ samples were cut from the stems of infected cashew plants and transported to the microscope facility. Epifluorescence microscopy was performed on inoculate stems at 25 and 45 days postinoculation (dpi).

\section{Expression analysis of reporter GFP}

The green fluorescence emission associated with GFP was detected using a Leica UV epifluorescence microscope (DMKLB, Leica Microsystems, Germany), with the following filter settings: $488 \mathrm{~nm}$ excitation and $515 \mathrm{~nm}$ emission.

\section{RESULTS}

The Hyg B minimum inhibitory concentration for L. theobromae was determined by the cultivation of monosporic cultures on PDA containing different Hyg B concentrations. Our results showed that fungal growth was completely inhibited by Hyg B at the minimal concentration of $150 \mu \mathrm{g} / \mathrm{mL}$; thus, this concentration was used for the initial selection of transformants.

A. tumefaciens harboring the binary vector pPm43GW-GFP-HPH efficiently transferred T-DNA to cells, which was confirmed by active fungal cell growth on SM. Hyg Bresistant mycelium cells were only obtained when the bacterial culture was induced with acetosyringone. When compared to wild-type strains, transformant colonies had the same mycelium growth rate, covering the full-plate area after 8 days of incubation. Trials for pycnidiospore production were also successful. Transgenic fungi obtained by Agrobacteri$u m$-transformation were microscopically analyzed to determine GFP expression, and its accumulation in mycelia, using epifluorescence microscopy (Figure 2). Fungal mycelia were directly collected from the selection plates, and visualized under fluorescence microscope using the appropriate filters for GFP. Wild-type and stable transformants were examined. Intense and bright green hyphae were observed in the transformants from all extension of the mycelium cultures. 


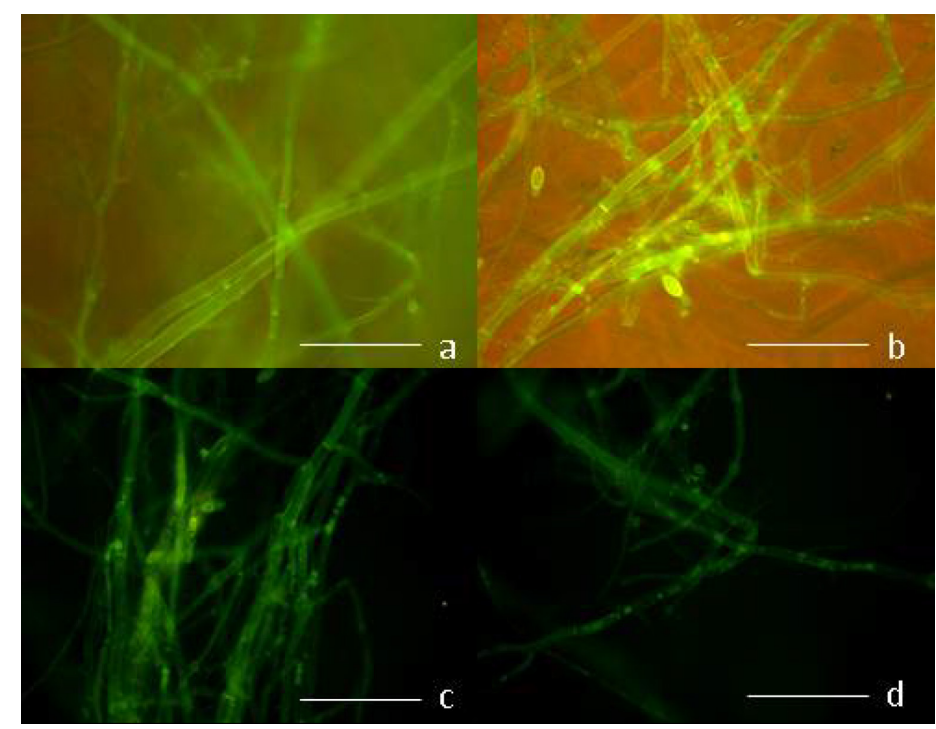

Figure 2. Expression of green fluorescent protein (GFP) examined by epifluorescence microscopy. GFP was found to be localized in hyphae of Lasiodiplodia theobromae $(\mathbf{a}, \mathbf{b}, \mathbf{c}, \mathbf{d})$. Fungal mycelia were directly taken from the selection plates and visualized. Bars $=60 \mu \mathrm{m}$.

To study host-pathogen interactions, cashew plants were inoculated with EGFP-transformed L. theobromae. Penetration of parenchyma cells near to the inoculation site (beneath the epicuticle surface) was observed before 25 dpi. Penetration was followed by the development of hyphae within the invaded host cells (Figure 3). After $45 \mathrm{dpi}$, the vessels also contained hyphae presenting green fluorescence under an epifluorescence microscope.

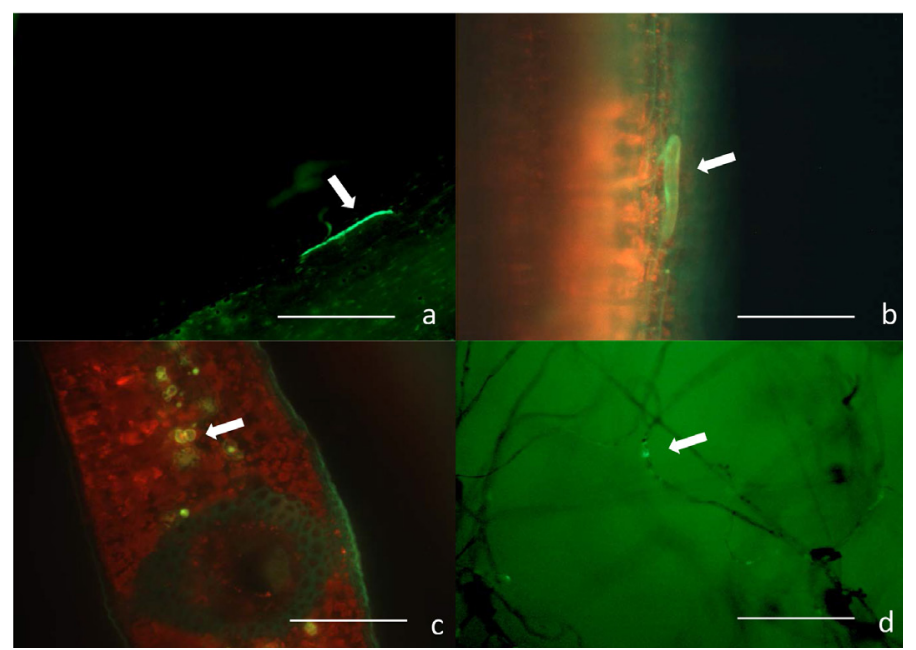

Figure 3. Interaction of GFP-Lasiodiplodia. theobromae with cashew plants examined by epifluorescence microscopy. Twenty-five days post-inoculation (dpi) $(\mathbf{a}$. bar $=100 \mu \mathrm{m}$; b. bar $=50 \mu \mathrm{m})$ and 45 dpi $(\mathbf{c}$. d. bar $=100$ $\mu \mathrm{m})$. White arrows $=$ GFP-L. theobromae. 


\section{DISCUSSION}

This study is the first report to describe an efficient system for ATMT for L. theobromae, with the protocol appearing to be simple and reproducible. A. tumefaciens-T-DNA transfer has been extensively proven to be an efficient transformation system for filamentous fungi (Nizam et al., 2010; Vieira and Camilo, 2011; Maruthachalam et al., 2012). The binary vector $\mathrm{pPm} 43 \mathrm{GW}-\mathrm{GFP}-\mathrm{HPH}$, containing cassette with $E$. coli $h p h$-resistance gene under the regulation of the Aspergillus nidulans trpC promoter and the PtGFP cassette containing the promoter toxA-5'-UTR from Pyrenophora tritici-repentis, was successfully employed. Hyg B inhibited the growth of wild-type $L$. theobromae; hence, we confirmed that it is a reliable selection marker.

ATMT serves as an effective tool for the genetic transformation of a wide variety of filamentous fungi. In the present study, a protocol for the ATMT of L. theobromae was developed. Agrobacterium has been reported to transform fungal conidia, spores, hyphal tissue, and protoplasts. Here, pycnidiospores, which are conidia produced by the fungus, were employed as fungal transformation targets. Species of Lasiodiplodia are easily cultivated on artificial media, presenting fast mycelial growth. Yet, sporulation may be a difficult task under certain circumstances. For instance, sporulation efficiency may be negatively compromised by certain temperature, light, and substrate regimes. Previously, a method developed for pycnidiospore production involved the use of PDA medium supplemented with $10 \%$ mung bean extract (1000 g mung beans boiled in 2-L deionized water) and incubation of the cultures at $25^{\circ} \mathrm{C}$ for 5 days (Muniz et al., 2012). Since this method proved to be efficient, employment of these structures as the biological target for ATMT seems to be appropriate.

Transformed fungal viability was observed. Transformant cultures presented the same growth rate and pycnidiospore production ability of wild-type strains. Therefore, these transformant cultures appear able to be inoculated in plants in the same way as the wild-type cultures, which would facilitate detailed pathogenesis investigations. GFP has been used to monitor the behavior of filamentous fungi in real time during host-parasite interactions. This has facilitated the study of various aspects of microbial behavior, such as in vitro germination, hyphal penetration, host invasion, and inner distribution. Documentation of GFP expression, both in vitro and in vivo, helps researchers to understand mechanisms of fungal entry, in addition to providing information about the interference of transformation on fungal inner distribution or pathogenicity abilities (Li et al., 2011; Moročko-Bičevska and Fatehi, 2011). GFP-transformed L. theobromae was inoculated in cashew plants, and presented the same distribution behavior observed in previous microscopic investigations. The occurrence of hyphal parenchyma, along with the presence of fungi in nearby vessels, was also detected in this study, supporting the study of Muniz et al. (2011). This observed pattern of distribution pattern confirms the ability of this fungus to widely colonize the inner tissues of the plant, with the fungus easily spreading across the cell walls.

The ability to introduce foreign DNA into a fungus is considered the pillar of modern fungal genetics. The efficient ATMT system developed here for $L$. theobromae represents an important step toward advancing functional genomic studies involving a wide range of experiments, including random mutagenesis, gene knockout and gene knockdown utilized to identify which genes are essential for pathogenicity. In conclusion, the efficient ATMT system developed here is anticipated to help design new strategies for disease control. 


\section{ACKNOWLEDGMENTS}

We thank CAPES (Coordenação de Aperfeiçoamento de Pessoal de Nível Superior) for the scholarship, the "Brazil-Netherlands" Program that enables Brazilian students to participate as foreign fellows at Wageningen University, Embrapa Labex, Netherlands, for logistics and financial support, and Carlos Antônio Ferreira de Sousa for his invaluable agronomy advice.

\section{REFERENCES}

Ando A, Sumida Y, Negoro H, Suroto DA, et al. (2009). Establishment of Agrobacterium tumefaciens-mediated transformation of an oleaginous fungus, Mortierella alpina 1S-4, and its application for eicosapentaenoic acid producer breeding. Appl. Environ. Microbiol. 75: 5529-5535.

Blaise F, Rémy E, Meyer M, Zhou L, et al. (2007). A critical assessment of Agrobacterium tumefaciens-mediated transformation as a tool for pathogenicity gene discovery in the phytopathogenic fungus Leptosphaeria maculans. Fungal. Genet. Biol. 44: 123-138.

Cardoso JE, Cavalcanti JJV, Cysne AQ, Sousa TRM, et al. (2010). Interação enxerto e porta-enxerto na incidência da resinose do cajueiro. Rev. Bras. Frutic. 32: 847-854.

Casas-Flores S, Rosales-Saavedra T and Herrera-Estrella A (2004). Three decades of fungal transformation: novel technologies. Methods Mol. Biol. 267: 315-325.

de Groot MJ, Bundock P, Hooykaas PJ and Beijersbergen AG (1998). Agrobacterium tumefaciens-mediated transformation of filamentous fungi. Nat. Biotechnol. 16: 839-842.

dos Reis MC, Pelegrinelli Fungaro MH, Delgado Duarte RT, Furlaneto L, et al. (2004). Agrobacterium tumefaciensmediated genetic transformation of the entomopathogenic fungus Beauveria bassiana. J. Microbiol. Methods 58: 197-202.

Freire FCO (1991). A resinose do cajueiro (The cashew gummosis). Caju Informativo, EMBRAPA-CNPCa 4: 1-2.

Freire FCO, Viana FMP, Cardoso JE and Santos AA (2004). Novos hospedeiros do fungo Lasiodiplodia theobromae no Estado do Ceará. Comunicado Técnico Embrapa ISSN 1679-6535 91: 1-6.

Hoekema A, Hirsch PR, Hooykaas PJJ and Schilperoort RA (1983). A binary plant vector strategy based on separation of vir- and T-region of the Agrobacterium tumefaciens Ti-plasmid. Nature 303: 179-180.

Li C, Chen S, Zuo C, Sun Q, et al. (2011). The use of GFP-transformed isolates to study infection of banana with Fusarium oxysporum f. sp. cubense race 4. Eur. J. Plant Pathol. 131: 327-340.

Maruthachalam K, Jeon J, Lee YH and Subbarao KV (2012). Identification of Fungal Pathogenicity Genes by Agrobacterium Tumefaciens-Mediated Transformation. In: Biotechnology of fungal genes (Gupta VK, ed.). Science Publishers, Enfield, 1-20.

Michielse CB, Hooykaas PJ, van den Hondel CA and Ram AF (2005). Agrobacterium-mediated transformation as a tool for functional genomics in fungi. Curr. Genet. 48: 1-17.

Moročko-Bičevska I and Fatehi J (2011). Infection and colonization of strawberry by Gnomonia fragariae strain expressing green fluorescent protein. Eur. J. Plant Pathol. 129: 567-577.

Muniz CR, Freire FC, Viana FM, Cardoso JE, et al. (2011). Colonization of cashew plants by Lasiodiplodia theobromae: microscopical features. Micron 42: 419-428.

Muniz CR, Freire FCO, Viana FMP, Cardoso JE, et al. (2012). Polyclonal antibody-based ELISA in combination with specific PCR amplification of internal transcribed spacer regions for the detection and quantitation of Lasiodiplodia theobromae, causal agent of gummosis in cashew nut plants. Ann. Appl. Biol. 160: 217-224.

Nizam S, Singh K and Verma PK (2010). Expression of the fluorescent proteins DsRed and EGFP to visualize early events of colonization of the chickpea blight fungus Ascochyta rabiei. Curr. Genet. 56: 391-399.

Sharma KK and Kuhad RC (2010). Genetic transformation of lignin degrading fungi facilitated by Agrobacterium tumefaciens. BMC Biotechnol. 10: 67.

Staats CC, Junges A, Fitarelli M, Furlaneto MC, et al. (2007). Gene inactivation mediated by Agrobacterium tumefaciens in the filamentous fungi Metarhizium anisopliae. Appl. Microbiol. Biotechnol. 76: 945-950.

Vieira AL and Camilo CM (2011). Agrobacterium tumefasciens-mediated transformation of the aquatic fungus Blastocladiella emersonii. Fungal. Genet. Biol. 48: 806-811.

Ward OP (2012). Production of recombinant proteins by filamentous fungi. Biotechnol. Adv. 30: 1119-1139.

Genetics and Molecular Research 13 (2): 2906-2913 (2014)

CFUNPEC-RP www.funpecrp.com.br 